\title{
LO EDUCATIVO EN EL HORIZONTE DE LA PRAXIS Y POIESIS: SU COMPONENTE DE CONTINGENCIA
}

Education on the Horizon of Praxis and Poiesis: Its Component of Contingency

PATRICIA DUCOING WATTY

IISUE-UNIVERSIDAD NACIONAL DE MÉXICO (MÉXICO)

PDUCOINGW@GMAIL.COM

ORCID: 0000-0001-7980-8712

DOI: https://doi.org/10.5565/rev/mitologias.817

vol. 25 | enero 2022 | 21-37

Recibido: 01/09/2021 | Aceptado: 28/09/2021

Resumen:

Este artículo tiene como objetivo elucidar sobre la educación y la formación en el horizonte de la praxis, conceptualizada como un proceso complejo, signado por la fragilidad, la incertidumbre, la contingencia y la incompletud, en el cual los sujetos se reencuentran cara a cara e interactúan en la cotidianeidad. La visión praxística se contrasta con la perspectiva de la poiesis, en la cual la certeza del hacer productivo, de corte técnico-instrumental, conduce a eludir la existencia de los otros como seres autónomos y singulares, bajo el supuesto de garantizar la obtención de un producto externo: competencias, saberes, capacidades, habilidades.

Palabras clave:

Educación, formación, praxis, poiesis, imprevisibilidad, fragilidad 


\section{Abstract:}

The purpose of this article is to explain, from a praxis perspective, the terms education and training, considered as a complex process, where individuals face each other and interact in a common environment polluted by certain aspects such as fragility, uncertainty contingency and partiality. The praxistic position contrasts with the poiesis perspective in which the certainty of technical-instrumental production eludes the existence of other persons as autonomous and remarkable beings under the assumption that there will be external products such as knowledge, competencies, skills.

\section{Keywords:}

Education, Training, Praxis, Poiesis, Unpredictability, Fragility 


\section{Introducción}

Tras una sucinta entrada sobre la irrupción de la pandemia del COVID-19 y sus devastadores efectos, este texto se encuentra estructurado de la siguiente forma: como inicio se efectúa un acercamiento a la noción de contingente en un primer apartado intitulado "Un breve recorrido conceptual". Posteriormente, con el propósito de situar lo educativo en el campo de la acción, se revisa la distinción entre praxis y poiesis, que categóricamente formula Hannah Arendt (2013) en consonancia con el tratamiento aristotélico, bajo el subtítulo "La actividad humana desde la praxis y la poiesis: de la tradición aristotélica al pensamiento arendtiano". En la tercera y última sección de este artículo, "El acontecer formativo y educativo: ámbito de la praxis", se destaca la naturaleza inmanente de las prácticas educativas, la autonomía en el horizonte de la praxis, y la contingencia o los límites de la formación y la educación. Se cierra este artículo con unas reflexiones finales.

El objetivo fundamental de este ensayo consiste en reconocer la especificidad y singularidad de la educación como praxis y establecer el lugar que la contingencia y la incertidumbre ocupan en el espacio/tiempo educativo y formativo a fin de considerarlas como una dimensión constitutiva de lo humano, de lo social y de la educación. Partimos del hecho relativo a que en todos los escenarios institucionales se despliegan interacciones entre entre los sujetos, cuyas acciones y palabras — en el marco de la concepción praxística de lo educativo- pueden emerger rompiendo el curso de lo que, en principio, es considerado como un proceso habitual. Si bien en el campo educativo hay un gran ámbito para la previsibilidad con base en la planeación y organización de las prácticas institucionales, el análisis de lo no previsto, de lo no esperado, es usualmente eludido, como si no existiese la posibilidad de su aparición en el campo de la formación universitaria y de la educación básica. Es posible formular que tanto la previsibilidad como la imprevisibilidad se configuran como dimensiones sustantivas de la educación. Efectivamente, lo inesperado ha sido frecuentemente desatendido, si no es que excluido, en las elucidaciones sobre las prácticas educativas, las cuales se centran en el carácter situado de la ilimitación de lo posible, de los posibles.

En la historia de la humanidad se ha experimentado un buen número de acontecimientos o eventos abruptos que han trastocado el curso de la vida política, económica y social de las naciones y sus pobladores, tales como un descubrimiento científico, una epidemia, una guerra, una catástrofe natural, la instauración de un régimen autoritario, entre otros muchos.

La pandemia del COVID, visualizada como contingencia, e iniciada a fines de 2019 y extendida en el mundo entero, nos condujo a cambiar completamente los ritmos de vida y las específicas temporalidades humanas y sociales. Estas últimas fueron signadas por el obligatorio confinamiento y las grandes limitaciones en las actividades cotidianas, todo esto acompañado además por importantes consecuencias económicas, políticas, culturales, salariales, nutricionales y climáticas. Somos testigos del efecto devastador de esta pandemia en todos los sectores, particularmente en los países en desarrollo, los cuales han experimentado una franca degradación de su situación alimentaria, económica, sanitaria, psíquica-afectiva, de seguridad y, por supuesto, educativa. En efecto, a causa de la paralización de actividades, de la pérdida de empleos, de la disminución de salarios, entre otros tópicos, las poblaciones vulnerables — desplazados, migrantes, habitantes en zonas de conflicto y de pobreza, y de pobreza extrema - se han visto mayormente afectadas.

La naturaleza contingente e imprevista de la pandemia del COVID en el contexto internacional hizo su aparición desestabilizando los sistemas educativos y trastocando el curso institucional de la docencia en todos los niveles. Sin embargo, no es esta pandemia el único acontecimiento portador de lo no previsto, sino contrariamente, en la vida cotidiana de los actores sociales y de las instituciones educativas y de formación, la imprevisibilidad representa una dimensión constitutiva de ese acontecer educativo en el que se despliegan las acciones e interacciones de los hombres, de los estudiantes y de los 
docentes. Por tanto, es imperativo el reconocimiento y la aceptación de las contingencias y los imprevistos en el escenario de la educación, los cuales irrumpen y se imponen en la cotidianeidad áulica a través de situaciones fortuitas, repentinas, accidentales, en fin, posibles, que escapan a toda posibilidad de control.

\section{Un breve recorrido conceptual sobre la contingencia}

De entrada, exploramos muy resumidamente algunos de los significados que en el tiempo se han atribuido al vocablo contingencia, para lo cual iniciamos con su dimensión denotativa. El término de contingencia proviene del bajo latín de la filosofía, contingentia, y es comprendido como "posibilidad de que algo pase o no pase", "lo que puede o no puede ser, casualidad" (Centre National de Ressources Textuelles et Lexicales, 2012: s/p). Se le asocian como sinónimos azar, eventualidad, circunstancia, incertidumbre, imprevisibilidad, entre otros, oponiéndose al de necesidad, al de determinismo.

En la Antigüedad, el tema de la contingencia fue abordado en vinculación con la idea de la necesidad. De hecho, el debate se centró durante mucho tiempo entre la contingencia y el indeterminismo y el determinismo. En oposición a los determinismos fatalistas, Aristóteles atribuye a la categoría de contingencia un valor de naturaleza ontológica, al conceptuarla como elemento constitutivo del mundo de la vida y al insistir en su elucidación relativa a que las cosas pueden ser diferentes, distintas a lo que son, es decir, las cosas pueden ser o no ser. En palabras del filósofo:

$[\ldots]$ nunca deliberamos sobre las cosas que no pueden ser de otra manera de lo que son [...]; por tanto, si es cierto que una ciencia va acompañada de demostración, pero que las cosas cuyos principios pueden ser distintos de los que son admitidos (porque es igualmente probable que todos sean de otra manera de lo que son) [...] porque el objeto de la acción puede ser distinto de lo que es [...]. (Aristóteles, 2014: 134)

A propósito de este planteamiento señala Lledó: "Precisamente porque la vida es ambigua, y el azar la ciñe, no podemos pedirle una precisión que la convertiría en 'automática' (autómaton) y empobrecería, por consiguiente, sus posibilidades” (en Aristóteles, 1988: 73).

Si bien son varios los filósofos contemporáneos que han elucidado y reivindicado la temática de la contingencia, es de destacar, entre los existencialistas del siglo XX, a Sartre y a Heidegger. El primero con su obra inicialmente considerada como un "Factum 1 sobre la contingencia", la cual fue finalmente publicada en 1938 bajo el título de La Náusea (Sartre, 2004), que, como género literario, integra su reflexión filosófica y la dramatización literaria; de ahí que se le identifique como una novela filosófica, aun cuando, en realidad, el pensador no elucida sobre la náusea en sí, sino sobre lo que la provoca, es decir, la contingencia.

Heidegger (1951), por su parte, en su reflexión analítica existencial, reivindica la contingencia al aludir al carácter limitado, finito y frágil de la naturaleza humana, del "ser ahî", como un modo de ser que le es propio, que lo singulariza y que lo conduce a su destino histórico: la muerte. Es esta, la muerte, un elemento constitutivo del ser mismo, del Dasein, signado por su radical contingencia histórica, identificada como "ser hacia la muerte". En efecto, al preguntarse sobre el ser, advierte la cuestión de la temporalidad

\footnotetext{
${ }^{1}$ El vocablo factum designaba situaciones de la cotidianeidad en tanto relato de la existencia de los hombres, es decir, de la condición humana.
} 
del ser, del "ser ahî" y con esta, la temática relativa a la muerte, es decir, la finitud del "ser ahî", imposible de controlar.

En la actualidad y en general la noción de contingencia, de la misma manera que las de términos como imprevisto, incertidumbre, impredecible e imprevisible, forma parte posiblemente de un campo semántico, al compartir todos ellos varios rasgos de su significado, rasgos que signan las acciones del hombre y, en consecuencia, de la educación. Este vocablo es ampliamente movilizado, en las ciencias naturales y en las matemáticas, y análogamente en varias subdisciplinas específicas, tales como la sociología de las organizaciones, la psicología del trabajo, la psicología social, la gestión de recursos humanos, es decir, en varias profesiones, aunque en ocasiones desatendido en las ciencias humanas, las ciencias sociales y las de la educación. De ahí que se advierte la emergencia de otorgarle un lugar en la elucidación del acontecer formativo y educativo.

\section{La actividad humana desde la praxis y la poiesis: de la tradición aristotélica al pensamiento arendtiano}

Inspirada en el pensamiento aristotélico, mediante el cual Aristóteles distingue la poiesis de la praxis, Hanna Arendt, en su gran obra La condición bumana (2013), otorga un lugar a la acción en el mundo actual, es decir, a la praxis. Su obra, destinada al análisis de la condición humana, entre otras cuestiones recrea su visión sobre el estatuto del ser humano inscrito en una temporalidad y una espacialidad determinadas.

Partimos de una sucinta reflexión sobre el tratamiento que el filósofo formula sobre las nociones de praxis y poiesis para transitar, enseguida, al planteamiento arendtiano, influenciado tanto por la herencia aristotélica y marxista como por el pensamiento de Heidegger y Husserl, a fin de postular la acción como base fundante y central de lo educativo, en tanto elemento constitutivo de la singularidad de la praxis y, consecuentemente, de la educación, así como de su naturaleza histórica y de su carácter contingente.

Después de establecer una distinción respecto al "vivir" entre las plantas, los animales y los hombres, el filósofo griego jerarquiza el concepto de la vida de cada una de estas especies: la vida nutritiva, correspondiente a las plantas; la vida sensitiva, a los animales; y la vida activa, propia del hombre como ser racional. Aun cuando el hombre comparte con las plantas y los animales el hecho de vivir, él es el único que, además de poder pensar, tiene logos, es decir, que tiene palabra y discurso, mediante el cual todos los seres humanos se expresan. Es así que elucida que el hombre como ser racional, es decir, la humanidad, existe por el hecho de vivir, pero también de hablar y de actuar. Efectivamente, el filósofo griego plantea la especificidad de la vida del hombre en contraste con la de las plantas y los animales, aludiendo a la acción, a la praxis, que es portadora de un fin en sí misma, porque se trata de una acción inmanente, en la cual “[...] los principios de la acción son el propósito de esta acción”" (Aristóteles, 2014:134).

La distinción aristotélica entre la praxis y la poiesis radica en que, mientras la primera caracteriza el movimiento mismo de la vida, debido a que refiere al mismo sujeto —- "La vida es acción, no producción" (Aristóteles, 1988: 55)—, la segunda, la poiesis, remite a la producción de un objeto, de una obra exterior, producción que — en la teorización de Aristóteles - no tiene un fin en sentido absoluto, sino que se trata de la producción de una cosa determinada, la cual es distinta de la actividad que la produce. En términos del autor:

Las cosas que pueden ser distintas de lo que son incluyen tanto las cosas que fabricamos como las acciones que realizamos. Producción y acción son distintas (sobre su naturaleza podemos confiar en los discursos exotéricos); de ello se deduce que la disposición a actuar acompañada de la regla es diferente de la disposición a producir acompañada de una norma. De aquí se desprende que no son 
una parte de la otra, pues ni la acción es una producción, ni la producción una acción. (Aristóteles, 2014: 133)

Resulta relevante la oposición señalada entre la disposición racional para la acción y la disposición para la producción, al calificarlas como excluyentes. A este propósito, elucida el autor sobre la prudencia como una virtud, cuyo género se inscribe en la acción del hombre "capaz de actuar en la esfera de lo que es bueno o malo para el ser humano" (Aristóteles, 2014: 134); en otras palabras, la prudencia implica necesariamente una disposición susceptible de actuar en el ámbito de los bienes humanos. Inversamente, la disposición para la producción, para la construcción, refiere al orden de la práctica, del hacer en general, es decir, a la disposición racional capaz de producir una obra, un producto. Al aludir al arte, reitera el autor: "Como la producción y la acción son algo diferente, el arte debe pertenecer necesariamente a la producción y no a la acción. Y, en cierto sentido, la fortuna y el arte se relacionan con los mismos objetos" (Aristóteles, 2014: 133).

En suma, el trabajo que se despliega bajo el concepto de poiesis es, para Aristóteles, la techné, vinculada con la maestría o destreza para la creación, la fabricación y la construcción, cuyo producto queda concluido, mientras que el relativo al concepto de praxis no se extingue en ninguna obra, en tanto un ejercicio racional de la acción de los hombres.

Arendt se adhiere al pensamiento aristotélico a partir de un abordaje fenomenológico sobre el hombre y su condición en el mundo, al recobrar y reformular la distinción entre el hacer — poiesis - y el actuar — praxis_, elucidación relevante para la comprensión de la especificidad del hombre, en tanto sujeto de la praxis, así como para subrayar la crítica emprendida por la cual se busca remitir las prácticas fabriles, finitas y previsibles, a las concepciones y las prácticas tendentes a la formación del hombre, a la formación de la ciudadanía, a la educación, siempre imprevisibles.

Con base en el vocabulario categorial arendtiano podemos adentrarnos en varios de los conceptos básicos de su teorización sobre la inserción del hombre en el mundo, mundo cohabitado por otros hombres y por objetos que ellos fabrican, pero también mundo en el que la humanidad expande su actividad bajo diversas modalidades. La comprensión de la condición humana es la condición de la existencia humana tanto en sus dimensiones generales como en las particulares de cada hombre que actúa, signando así una diferencia en su propia existencia. Para la autora, todos los hombres estamos condicionados en vista de que, al entrar en contacto con las cosas, estas devienen en condicióndesu existencia.

La triple caracterización que efectúa Arendt sobre la vida activa de la humanidad, la labor, el trabajo y la acción — distinguiéndose de la vida contemplativa, la théorie — se corresponde respectivamente con el proceso biológico, con el mundo de las cosas (artificial) y con la acción, siendo esta última la que se despliega en el mundo por todos los hombres, a partir de la cual estos se revelan y diferencian a lo largo de su existencia. Al revalorar la acción, puntualiza la filósofa, es la "única actividad que se da entre los hombres sin la mediación de cosas [...], corresponde a la condición humana de la pluralidad" (Arendt, 1993: 22). Esta categoría de pluralidad es comprendida como la condición de la acción humana mediante la cual "todos somos lo mismo" (Arendt, 1993: 22), pero no por ello somos iguales, sino diferentes. Es con base en la acción y el discurso que los hombres se diferencian a pesar de compartir el hecho de todos ser humanos.

De las tres actividades de la vida activa, la acción es una dimensión central que conserva una mayor vinculación con la condición de la natalidad, como reitera la filósofa. La irrupción de esta categoría de natalidad en el discurso arendtiano cobra relevancia al invertir el planteamiento heideggeriano relativo al "ser para la muerte" y formularlo inversamente: "ser para la natalidad"; esto porque, si bien los hombres habremos de morir, hemos nacido para iniciar algo nuevo. La natalidad es un concepto que, vinculado con el nacimiento, se encuentra al fundamento de la acción, toda vez que denota la capacidad de iniciar algo nuevo, de comenzar algo que "no puede esperarse de cualquier cosa que haya ocurrido antes" 
(Arendt, 1993: 201). La libertad, propia de la condición humana, se corresponde con la capacidad de iniciativa, capacidad de poder comenzar. Todo inicio, como el del nacimiento, significa entrar al mundo y toda acción, en tanto comienzo, implica necesariamente insertarse o reinsertarse en el mundo. La teorización de Arendt sobre el comienzo se encuentra enraizada en el vínculo que se genera entre palabra y acción de los hombres, constituyendo un elemento central de su filosofía: es por el discurso que la acción adquiere sentido. Por lo tanto, la naturaleza reveladora de la acción se funda en el discurso, el cual es conceptuado como condición de la acción.

Si la acción como comienzo corresponde al hecho de nacer, si es la realización de la condición humana de la natalidad, entonces el discurso corresponde al hecho de la distinción y es la realización de la condición humana de la pluralidad, es decir, de vivir como ser distinto y único entre iguales. (Arendt, 1993: 202)

Considerar el carácter radicalmente novedoso de toda acción como comienzo, como inicio, requiere el reconocimiento de que esta se encuentra signada por la irrupción de la imprevisibilidad, de la irreversibilidad, de la incertidumbre: "El hecho de que el hombre sea capaz de acción significa que cabe esperar de él lo inesperado, que es capaz de realizar lo infinitamente improbable" (Arendt, 1993: 202).

En consecuencia, las acciones humanas, y entre ellas la educación, se encuentran signadas por la contingencia, la cual se configura como una categoría estrechamente vinculada con la imprevisibilidad, comprendida esta como algo que no es posible anticipar, prever. De ahí que lo no esperado en el campo educativo representa un elemento constitutivo de las prácticas que se desarrollan en las instituciones de educación, en tanto prácticas desplegadas por los hombres.

En franco antagonismo con el concepto de praxis, Arendt plantea — dando continuidad a la formulación aristotélica - el de poiesis, atribuido al homo faber, es decir, el referido al trabajo del hombre, a la fabricación de objetos, los cuales constituyen lo que denomina el "artificio humano", que se configura en una cadena utilitarista, creando un mundo artificial de objetos que son los que adquieren un valor. La construcción de objetos es realizada con base en un modelo, un plan, una idea, que es la guía para su elaboración, mediante la cual se moviliza una técnica que conduce a la obtención de un producto. De hecho, el objeto elaborado es un producto final, terminado, acabado, con el que concluye el proceso de producción, aun cuando pueda reiniciarse el proceso, dada su condición de reversibilidad. En consecuencia, en el escenario de la poiesis, se tiene un inicio y un fin establecido, cuyo proceso es mediado por la instrumentalidad. La utilidad y la conveniencia, características del hacer, están acompañadas de la intencionalidad del uso.

El hacer, la poiesis, se basa en el esquema de medios y fines. Los medios conducen a la obtención de los fines y, por tanto, están justificados con base en esos fines, marcando con esto una distancia con respecto a la labor y a la acción. En el hacer, y a diferencia de la acción, hay una obra exterior al hombre, que implica un saber-hacer de conformidad con el modelo. De esta forma, Arendt formula el concepto de poiesis por oposición radical con respecto al de praxis y, por supuesto, al saber contemplativo. En contraste con la acción, caracterizada por la imprevisibilidad y la fragilidad, en la poiesis es posible la previsión, el control, la predicción, la reversibilidad y una cierta garantía del éxito en la manufactura de objetos, fundada en la techné, o sea, un saber específico de corte instrumental. Se trata de una actividad transitiva de naturaleza clausurante, cuyo producto existe independientemente de la actividad desplegada en el proceso de manufactura (Castoriadis, 1975).

En la visión poiética de lo educativo se cree garantizar los objetivos estipulados con base en las programaciones o planeaciones diseñadas por las instituciones o bien por el propio profesor, lo que significa la inscripción de la acción humana y de la educación en un registro de corte técnico, que niega la contingencia, la imprevisibilidad y lo no esperado de las acciones de los alumnos y del docente. Inversamente, desde la mirada praxistica se reconoce la naturaleza contingente, imprevisible en el 
desarrollo de las prácticas educativas, tales como la falta de interés de los alumnos respecto a la temática que se está abordando, su apatía en relación con la disciplina que se trabaja, su falta de compromiso por aprender, su carencia de empatía con el profesor o, inversamente, su toma de la palabra para enriquecer lo que se está desarrollando, sus preguntas para aclaraciones, sus intervenciones que ejemplifican, entre muchos más, tópicos que es preciso reconocer, aceptar y enfrentar.

\section{El acontecer educativo y formativo: ámbito de la praxis}

En el marco de la teorización de Arendt sobre la vida activa, y la praxis como como categoría central de su filosofía, ${ }^{2}$ inscribimos lo educativo, en tanto acción intrínseca de lo humano, insistiendo con ello al llamado de la autora y de algunos pensadores como Castoriadis e Imbert, entre otros, sobre el peligro de la reducción de la praxis y de las prácticas educativas —análogamente al de todas las prácticas sociales - a la simple manufactura de un objeto previamente determinado.

Solo a partir de una elucidación de las prácticas educativas como praxis y su distanciamiento de la poiesis es posible comprender la responsabilidad y las implicaciones que de esta se derivan. Actuar en materia educativa significa ser capaz de iniciativa, de comenzar algo nuevo, de innovar, de ser libre, debido a que toda acción supone libertad. Es así como, en el marco de la reflexión sobre la facultad humana de la acción y, por tanto, de la educación, es imposible eludir la presencia de la incertidumbre, de la imprevisibilidad, de la contingencia, y reconocer la fragilidad de los actos, categorías que no pueden ser comprendidas como excepción, sino como conceptos constitutivos del registro educativo y formativo. La intención consiste en arribar a la comprensión de lo educativo a partir de un cambio de significado que, desplazando la visión técnico-instrumental (poiesis), de tendencia fabril, se resitúe en la racionalidad praxística con base en las categorías filosóficas formuladas desde la tradición griega y reactualizadas por pensadores contemporáneos. La perspectiva por la cual muchos teóricos o practicantes se afilian a la visión poiética de la fabricación se funda en la seguridad de la que es portador el "hacer", de cara a la fragilidad e imprevisibilidad de la acción y, consecuentemente, de la educación.

Punteamos a continuación algunas categorías analíticas del acontecer práxico de lo educativo y formativo, cuya configuración como articulaciones singulares posibilitan una mirada de corte multirreferencial, signada por lo complejo, lo histórico, lo político, lo social y, evidentemente, por lo humano. Reconceptualizar lo pedagógico que es praxis representa la posibilidad de avanzar en el camino hacia la inteligibilidad de los procesos y las prácticas educativas. Partimos de las aportaciones filosóficopolíticas de estos pensadores que puntean ciertas relaciones con la educación, sin por ello reducir el término "educación" a su expresión correspondiente a la escolarización de niños en la educación básica, sino como un proceso que alude a la formación humana en general.

\section{a) Lo educativo y su fin inmanente}

El encuentro entre lo educativo y la praxis se teje en oposición a la frecuente concepción de la educación como técnica, en la que la lógica de las categorías de medios y fines es la privilegiada, bajo cuya racionalidad se comprende que el fin, el resultado, requiere del dominio, de la capacidad, de la habilidad del agente para transformar un material dado, al tenor de una máquina que puede reproducir un objeto con base en un modelo. En definitiva, en el hacer de la poiesis estamos frente a un proceso de reificación, de estatificación, dada su posibilidad de multiplicación, propia del mundo industrial y empresarial. A este propósito, es frecuente escuchar discursos de funcionarios y profesores, tales como: "se debe aplicar el

\footnotetext{
${ }^{2}$ Pese a que todo el desarrollo de Arendt gira en torno a lo político.
} 
programa para alcanzar los objetivos previstos y luego evaluar", para lo cual habría que hacer uso de los medios y de las estrategias conceptuadas como supuesta garantía para la obtención de los resultados. El modelo transitivo de enseñanza planteado se inscribe en una perspectiva mecánico-instrumental de la eficacia bajo la premisa de que el fin — los objetivos de aprendizaje - representan el producto terminado de una vez por todas — resultados observables_- y los medios, así como las condiciones —actividades de enseñanza que despliega el profesor, instrumentos, recursos- son justificados y están condicionados por el producto final, como objeto reificado y susceptible de ser reproducido, es decir, con la posibilidad de reiniciarse tantas veces por los profesores como se les prescriba, independientemente de las especificidades de los sujetos, de los grupos, de las instituciones, de la temporalidad e historicidad, así como de las situaciones contextuales.

Respecto a esa perspectiva clausurante, Imbert puntualiza que esta posición que enaltece la tecnificación se refiere: "a una práctica pedagógica tradicionalmente definida en torno a la identificación, al ordenamiento y al control de diferentes elementos que intervienen en el tiempo y el espacio escolar" (1992: 79). Indudablemente en esta visión del hacer pedagógico, basado en "un modelo", "una programación", se niega la presencia del sujeto, del estudiante como sujeto epistémico, como sujeto social, como sujeto afectivo-emocional, capaz de irrumpir y entorpecer la programación definida y las estrategias previstas por el profesor. Por tanto, no hay posibilidad de la revelación del sujeto, de los sujetos, sino la ausencia del ser como sujeto histórico, cuyo discurso y acción no tienen cabida. "La problemática del deseo, del sentido, vienen entonces a interferir con los cálculos estratégicos y las lógicas del hacer"; "Personas y sujetos se encuentran necesariamente reducidos al estado de individuos, es decir, de ejemplares, pensados en términos de serialidad" (Ardoino, 1994: 109-112).

Situadas ahora en la perspectiva de la praxis, en la cual el sujeto hace su aparición como ser singular con posibilidad de deseos, de imaginarios, de discurso y de acción, las prácticas educativas se resisten radicalmente a la poiesis y se vinculan con el concepto arendtiano de natalidad, como arriba se destacó, es decir, con la prerrogativa del ser humano, del profesor, del maestro, igual que de los alumnos, para iniciar algo nuevo, para tomar una iniciativa y revelarse ante los otros como seres humanos singulares que se encuentran e interactúan y de quienes es posible esperar lo no previsto.

Educar, enseñar, formar pertenecen al ámbito de la acción, de la apertura, de la ruptura, de lo posible, del inacabamiento, del inicio que no tiene fin. En la praxis, igual que en las prácticas educativas y las prácticas docentes, la formación del estudiante, del joven, no es un fin, debido a que el proceso formativo, el proceso de aprendizaje, adquiere significado en la propia acción de los sujetos. Aquí, los medios para alcanzar el fin son, de hecho, el fin mismo, siempre imprevisible, inversamente a la estructura de la racionalidad técnica, debido a que no se trata de un fin exterior al sujeto. La realización del hombre y su formación, a través de la acción, son de naturaleza esencialmente inmanente y se oponen a la visión tecnocrática, al desechar la cadena de medios y fines, y al asumir el carácter inextinguible de toda acción, de toda práctica educativa. Esta conceptualización de inmanencia comprendida como renovación constante de la vida del hombre, en tanto ser vivo, es formulada así por Deleuze: "Se dirá de la pura inmanencia que es UNA VIDA, y nada más. No es inmanencia a la vida, pero la inmanencia que no es nada es vida en sí misma. Una vida es la inmanencia de la inmanencia, la inmanencia absoluta: ella es poder y bienaventuranza" (1995: 7; mayúsculas del original). La formación del hombre en el horizonte praxístico habría de comprenderse como el proceso de humanizar-se en ese movimiento de la inmanencia de la vida. 


\section{b) Acontecer educativo y autonomía}

Desde la perspectiva de la praxis, el proceso formativo y educativo mantiene un fuerte lazo con la autonomía de los sujetos y su mismo proceso de autonomización. Si para Arendt la libertad es el rostro de la praxis, para Castoriadis, lo es la autonomía. En estos términos lo plantea Castoriadis (1975: 112): "Llamamos praxis ese actuar en el cual el otro o los otros son pensados como seres autónomos y considerados como el agente esencial del desarrollo de su propia autonomía". Para el autor, la especificidad de la praxis radica en el desarrollo de la autonomía del otro y de los otros, la cual no es un fin, sino un inicio, al ser esta, a la par, el medio y el fin, debido a que "la praxis pretende el desarrollo de la autonomía como fin y hace uso de la misma autonomía como medio" (Castoriadis, 1975: 112), es decir, la autonomía es para sí misma su realización, la realización del proceso emancipador.

De acuerdo con Arendt (1972), la cultura refiere al modo de la relación de los hombres con el mundo, y la autonomía consiste en la capacidad y responsabilidad del ser humano para actuar en este mundo ritmado por la temporalidad y conformado por una pluralidad de hombres, a través de muchas generaciones; esta tarea es asignada por la autora a padres y, particularmente, a maestros y profesores, en el marco institucional, a fin de garantizar "la continuidad del mundo [...] este mundo que tiene necesidad de una protección que le impida ser devastado y destruido [...]" (Arendt, 1972: 239). En este sentido, reitera Foray que esta responsabilidad sobre la continuidad del mundo solo puede darse si el sujeto autónomo tiene capacidad de optar y actuar por sí mismo en esta tierra que nos es común.

[...] el ser humano se constituye como sujeto dispuesto a asumir esta responsabilidad, es decir, suficientemente apegado al mundo, por un lado, y capaz de iniciativa, acción creativa, por el otro. Consecuentemente, los dos polos de la educación (mundo y sujeto) se refieren entre sí: la continuación del mundo implica seres humanos capaces de iniciativa; la capacidad de iniciativa solo tiene sentido en un mundo; la autonomía del ser humano solo puede ser autonomía de "un ser en el mundo". (Foray, 2001: 84)

En el pensamiento de Castoriadis, la educación ocupa un lugar importante en el marco de la triada freudiana de las profesiones imposibles — gobernar, educar y sanar-, en las cuales, la imposibilidad de su tarea se encuentra fundada en la incertidumbre de su triunfo, al considerar que, en educación, igual que en psicoanálisis y otros, las acciones se dirigen a ayudar al sujeto a devenir autónomo, capaz de reflexionar, capaz de optar y de actuar. Según Castoriadis (1975: 112), "La verdadera política, la verdadera pedagogía, la verdadera medicina, en la medida en que han existido, pertenecen a la praxis", como una acción consciente que solo puede darse en la lucidez y no con base en una lógica de 'aplicabilidad' de un saber siempre fragmentario. La praxis se apoya en el saber que es provisional, porque la acción conduce a la generación de nuevos saberes. Para el filósofo, la praxis "hace hablar al mundo en un lenguaje a la vez singular y universal. Esto es porque sus relaciones con la teoría, la verdadera teoría correctamente concebida, son infinitamente más íntimas y profundas que las de cualquier técnica o práctica 'rigurosamente racional" (Castoriadis, 1975: 113).

La paideia es comprendida por este pensador, filósofo y psicoanalista, como la cultura, es decir, la formación humana, la formación del sujeto a lo largo de la vida. El objetivo del quehacer formativo consiste en apoyar al sujeto, niño, adolescente o joven a devenir ser humano, ser humano autónomo, como él mismo lo prescribe:

La pedagogía debe en todo momento desarrollar la actividad propia del sujeto utilizando, por así decirlo, esta misma actividad propia. El objeto de la pedagogía no es enseñar materias específicas, sino desarrollar la capacidad de aprender del sujeto. [...] Las materias enseñadas deben ser consideradas como escalones o puntos de apoyo útiles, no sólo para hacer posible la enseñanza de un número creciente de materias, sino para desarrollar las capacidades de aprender, descubrir e inventar. (Castoriadis, 2000: 182) 
Castoriadis vincula la praxis con la educación y la responsabilidad de esta para promover la autonomía, aquí comprendida como una acción consciente y reflexiva que permita a los sujetos definir y hacerse cargo de su devenir, una educación de la autonomía y para la autonomía. El proyecto de autonomía en su doble dimensión —individual y colectiva-, al que otorga una centralidad el autor, refiere al proceso de autoalteración de los sujetos, pero también de la sociedad, una sociedad dotada de instituciones democráticas. El elemento fundante de su proyecto de autonomía descansa en el derecho del que gozan todos los individuos y la sociedad en su conjunto para establecer las normas que han de regir sus vidas y la de las instituciones, estas últimas creaciones de aquella. Sin educación para la autonomía, sin educación democrática, no puede haber sociedad democrática como proyecto de una sociedad autónoma. En sus palabras: "[...] no se puede querer la autonomía sin quererla para todos, debido a que su realización solo puede conceptuarse como una obra colectiva" (Castoriadis, 1975: 159). De ahí que sea imposible pensar en sujetos autónomos y libres, sin una sociedad libre y autónoma; es este el proyecto del autor para hacer posible la autonomía individual y colectiva, en el que, análogamente a la práctica psicoanalítica, la práctica educativa ha de tender hacia la emancipación de los sujetos y hacia la promoción de la creatividad y la reflexión para la conducción de la vida personal y social. A este propósito es pertinente cuestionarnos cómo instaurar una perspectiva praxística en los escenarios de la formación y de la educación tendente a la autonomización de los estudiantes.

\section{c) Contingencia e incertidumbre en educación o los límites de la formación y la educación}

Como muchos filósofos y pensadores lo han explicitado, en la acción educativa, análogamente a cualquier otra acción del hombre, lo contingente es ineludible, como posibilidad de lo imposible. Lo imposible es aquí comprendido como aquello que adviene al margen de las condiciones de posibilidad previamente pensadas, anticipadas, planeadas, previstas.

Retomamos, primeramente, la categoría de acontecimiento, la cual se presenta frecuentemente como una pregunta en las obras de muy diversos pensadores, sin poder llegar al establecimiento de un concepto, en virtud de que es el propio acontecimiento el que estaría en posibilidad de explicarlo. De hecho, son varios los teóricos que han elucidado sobre el acontecimiento, entre los que se puede señalar a Derrida y a Arendt, ${ }^{3}$ quienes, de inspiración fenomenológica, conceptúan los fenómenos como acontecimientos. Si Derrida, en su filosofía de la deconstrucción, vincula el acontecimiento con lo imposible, y lo posible como imposible, Arendt lo enlaza con la natalidad, pero ambos apuntan la singularidad e imprevisibilidad de un acontecer al representar una ruptura al momento de aparecer.

El acontecimiento se formula, por tanto, como una dimensión nodal que atraviesa la cotidianeidad de las prácticas en el ámbito universitario, igual que en cualquier otro espacio-tiempo de formación y educación, irrumpiendo o incluso violentando el proceso que con anticipación se hubiese planteado. El acontecimiento acaece justo ahí, donde no era esperado, e implica una apertura a lo que viene, incluso una apertura al otro, a los otros.

Para Derrida, el acontecimiento es conceptuado como sorpresa, imprevisión, anti-anticipación, debido a que es imposible verlo llegar con anterioridad. Así lo enuncia: "Por su propia estructura, un acontecimiento es incondicionado: en ninguna parte es posible 'como tal', debe anunciarse 'como' imposible, impresentable [...]" (Derrida, 2003: 197), asegurando por ello que el anuncio es imposible. La posible imposibilidad del acontecimiento está signada por la singularidad, la historicidad y la temporalidad, y por la posible imposibilidad de su comprensión. La conceptualización del acontecimiento se encuentra enlazada con la inquietud respecto al otro, porque el acontecimiento es llegada, es la

\footnotetext{
${ }^{3}$ Igualmente es posible destacar a Badiou, en su obra L'être et l'événement de 1988; Marion, en varios de sus libros como Étant donné (1997), Réduction et donation (1989); Lévinas, en Le temps et l'autre (1979) y Les imprévus de l'histoire (1994), entre muchos más.
} 
aparición del otro, el advenimiento del otro; es una llegada imprevista, posible e imposible y, a la vez, indecible e impensable; esa llegada apela a la justicia y a la responsabilidad del otro, respecto a lo cual hay que tomar una decisión, pero esta decisión es la del otro:

Mi decisión no puede jamás ser la mía, es siempre la decisión del otro en mí y yo soy pasivo en la decisión. Para que una decisión fuese acontecimiento, para que interrumpa mi poder, mi capacidad, mi posible [...], se requiere que yo someta mi decisión, lo que es inaceptable lógicamente. Y quisiera, entonces, intentar elaborar un pensamiento de la decisión que sea siempre decisión del otro, porque yo soy responsable por el otro [...]; es el otro que decide en mí sin que por ello yo sea exonerado de 'mi' responsabilidad. (Derrida, 2001: 102)

En esencia, en la filosofía de la deconstrucción de Derrida, la recepción y acogida del otro se configuran como rasgos sustantivos de la alteridad, en cuya trama se teje el acontecimiento a través de la figura del otro, de los otros, de los estudiantes, de los colegas, en los escenarios donde el acontecer educativo y formativo se vive en la cotidianeidad institucional.

Ahora bien, en el marco de la filosofía arendtiana sobre la priorización de la acción, el acontecimiento deviene una categoría medular de su pensamiento filosófico en la teorización sobre la praxis, para cuya conceptualización la pensadora alude al tratamiento fenoménico del totalitarismo como un acontecimiento que rebasa toda posibilidad de explicación causal. Como previamente se planteó, en la elucidación sobre el acontecimiento, la filósofa otorga una centralidad en toda su obra a la natalidad, penetrando en su teorización filosófica, heredada del pensamiento de San Agustín, del cual retomó el concepto de initium, mediante el cual "los hombres toman la iniciativa, se aprestan a la acción", de donde conceptualiza natalidad como comienzo. Así lo expresa:

Este comienzo no es el mismo que el del mundo; no es el comienzo de algo, sino de alguien que es un principiante por sí mismo. Con la creación del hombre, el principio del comienzo entró en el propio mundo, que, claro está, no es más que otra forma de decir que el principio de la libertad se creó al crearse el hombre, no antes. (Arendt, 1993: 201)

La natalidad, en Arendt, significa un acontecimiento que representa una ruptura con lo presente $\mathrm{y}$, a su vez, la instauración de algo nuevo que cobra sentido en los hombres mediante la palabra y la acción, fundadas ambas en la libertad humana como fuente del mismo acontecimiento. La apuesta por la natalidad y no por la mortalidad en la elucidación arendtiana se funda en la apertura de lo nuevo como comienzo, de lo que es portador cada bebé que se incorpora al mundo, igual que cada educador, cada académico, cada docente que, con su acción y su palabra, en el acontecer formativo, busca la autoalteración de los sujetos y la renovación del mundo.

Acompañado de los vocablos de acontecimiento y natalidad, en el escenario de la acción educativa y formativa, el advenimiento, la llegada de lo no previsto, de lo sorpresivo, es siempre una aparición singular de alguien que abre la imprevisibilidad como una posibilidad, que - como previamente destacamos - se sustenta en la libertad humana, de acuerdo con Arendt. La imprevisibilidad del acontecimiento, instaurada en la natalidad, conduce al cambio de rumbo motivado por la ruptura, por la desestabilización del curso del desarrollo en los contextos de la educación y la formación, conduciendo a una iniciación, a una reconfiguración de los procesos preestablecidos.

Si bien la previsión y planeación en educación son relevantes y fundamentales en los escenarios institucionales de todo sistema educativo, negar o soslayar la incertidumbre, la improbabilidad, la imprevisibilidad de lo posible, significa someter las acciones humanas a la lógica del hacer, en tanto proceso controlable, finito, reproducible, fundado en una racionalidad instrumental en la que se proclama la técnica como el postulado privilegiado para la resolución de todos los problemas de la formación, la enseñanza, la educación y el aprendizaje, y se reivindica la eficacia como valor supremo. Como se ha 
venido reiterando, en la elucidación del hacer de la poiesis en educación, se despoja, se ignora al sujeto, al estudiante, quedando este sometido, reducido, al control e imposición del profesor, bajo el supuesto de garantizar la previsibilidad e irreversibilidad de las prácticas como si fuesen actividades productivas.

La tensión que se teje entre lo previsible y predecible, y lo contingente, lo imprevisible, ha existido siempre y continuará existiendo en el acontecer educativo como una constante de todas las acciones humanas y, en consecuencia, de todos los actores sociales y de todas las sociedades, y convoca a su elucidación al plantear cuestionamientos de corte epistemológico y metodológico.

La inteligibilidad de lo educativo reclama el reconocimiento de la singularidad de las prácticas educativas en el horizonte de la praxis, signadas por la contingencia y la no reproductibilidad, la no duplicabilidad, en abierta oposición a la dimensión estandarizante con la que se monta la presunción del hacer productor a través de la racionalidad técnica-instrumental. Esta dimensión de la contingencia, de lo no esperado requiere un tratamiento desde la singularidad de las acciones, dado que actuar en formación y educación supera la decisión y la planeación de actividades en la enseñanza, y reclama un reconocimiento del escenario educativo como zona de incertidumbre, en donde se entrama la especificidad de las reacciones, las resistencias, las motivaciones, las experiencias, los sentidos, los significados, los imaginarios de los sujetos, así como la del contexto áulico e institucional. En consecuencia, es preciso conceder un lugar a la naturaleza contingente y limitada de lo educativo, cuya singularidad no se atribuye exclusivamente a las acciones tendentes a la enseñanza y el aprendizaje de los estudiantes, sino también a las particulares circunstancias en las cuales estas se desarrollan, es decir, las acciones formativas y educativas se despliegan situadamente, en un contexto, lo que en etnometodología se denomina la indexicalidad (Garfinkel, 2006). De ahí que, de cara a la imposibilidad de predecir las acciones de los sujetos en el escenario de la educación y de la formación, aun cuando se tenga un plan de trabajo, una guía de acción, un proyecto formativo, estos solo representan un recurso para actuar en el aula en una específica situación —indexical—, que exige la capacidad del profesor para improvisar frente a lo inesperado y aprovechar las oportunidades que el contexto ofrece.

\section{Reflexión final}

La pandemia sanitaria, como acontecimiento imprevisto, impredecible, ha constituido realmente un hito en la historia de la educación y de la humanidad. Tras el cierre masivo de las instituciones educativas, la educación básica y la superior se vieron obligadas, de un día a otro, a efectuar un cambio radical para garantizar la continuidad de la escolarización y la formación, generando una situación inédita en el mundo entero en todos los niveles educativos. Esta intención de continuidad, asumida a nivel internacional, implicó la organización y coordinación, a marcha forzada, de todo el personal docente, del administrativo, de los equipos técnicos, de los padres de familia de cursos iniciales y de los estudiantes universitarios, obligando a todos a efectuar ajustes importantes: el paso de la enseñanza presencial a la a distancia mediada por la digitalización. Este nuevo escenario dejará en la memoria de los actores del mundo educativo - profesores y estudiantes — una marca indeleble en niños, jóvenes y adultos al haber trastocado la vida cotidiana de las escuelas y las universidades.

La dimensión de lo imprevisible, como previamente apuntamos, está presente en todos los procesos humanos y sociales, y se advierte constante en el campo de la docencia en cualquier nivel educativo, pese a que no ha sido objeto de elucidación teórica, sino contrariamente se ha buscado neutralizarla, en lugar de convertirla en un objeto de análisis para poder hacer frente de la mejor manera a las situaciones no esperadas, contingentes, y de integrarla para la toma de decisiones en el momento mismo en que se desarrolla la enseñanza. Así ratifica Perrenaud (1999) el lugar de lo imprevisto: 
La cuestión es tanto más crucial cuanto que se trata de actividades que se caracterizan por lo inesperado cada día. Al afirmar que enseñar es actuar en la urgencia y decidir en la incertidumbre, yo inscribía lo imprevisto en la estructura misma de la profesión de profesor. Yo defendía una concepción de la enseñanza en la que lo único verdaderamente sorprendente y desestabilizador sería que las cosas salieran exactamente como estaban previstas. (s/p)

Durante la contingencia, la distancia - "espacio o intervalo de lugar o de tiempo que media entre dos cosas o sucesos" (RAE, 2021) - entre los hombres se impuso como una medida y un símbolo de las restricciones sanitarias para minimizar la propagación del virus en la población mundial. El distanciamiento, comprendido "como acción y efecto de distanciar o distanciarse" (RAE, 2021) no alude exclusivamente a la brecha física que separa en el espacio objetos u hombres, sino a la distancia psíquica, social, afectivo-emocional, corporal, usualmente intencional respecto a algo o a alguien. Distancia y distanciamiento condujeron a hegemonizar la digitalización en educación a través de muy diversas plataformas y canales de comunicación, provocando, en el ámbito de la educación, un trastocamiento de la relación profesor-alumnos, alumnos-alumnos. El movimiento inesperado por la migración a lo digital, y el abandono de lo presencial nos interpela sobre ese "no contacto humano", ese aislamiento corporal y posiblemente psíquico-afectivo, ese distanciamiento en las aulas del escenario pandémico, que irruptivamente desestabilizó esos espacios-tiempos en donde se cohabitaba cotidianamente, ahora signados por una ruptura de las interacciones que se experimentaban en las instituciones en una realidad físico-temporal y en un entorno de proximidad y corporalidad.

El súbito e inesperado cambio al distanciamiento en el encuentro áulico natural, mediado ahora por la pantalla, confirma que el profesor, igual que los alumnos, ha transitado de un docente real a un docente virtual, sin que las instituciones y su personal estuviesen preparados para enfrentar y responder a esta emergencia, a esta contingencia educativa y humana.

Esta impredecible situación, admitida como una urgencia de excepción, se ha convertido en la actualidad en una rutina que, reiteramos, ha fracturado las relaciones verbales y no verbales, impidiendo las construcciones, elaboraciones y diálogos comunes - porque la palabra es relación y proximidad, como apunta Lévinas - e imposibilitando los cuerpos en movimiento que dan acceso a los otros seres humanos y sobre todo a sí-mismos. Muy frecuentemente, la digitalización, gracias a la imagen que muestra el cuerpo del otro a distancia, es visualizada en el escenario poiético con base en una gran necesidad de dominio y de control — por parte del profesor - del programa, de las actividades, de los tiempos, de los saberes, de las evaluaciones y, consecuentemente, de los estudiantes y sus obligaciones escolares y académicas, al permanecer separados el "yo real" de profesor y alumnos, del "yo digital”, el cuerpo real del cuerpo virtual.

La pantalla, como barrera de protección, coloca al otro afuera, en la posibilidad de incomunicación. En otras palabras, el otro está excluido a través de la pantalla de la computadora, de la laptop, de la tablet, como blindaje, como resguardo. La clase, ahora casi desprovista de la fragilidad, de la imprevisibilidad, se desarrolla en el contexto de la previsión, del aseguramiento de la aplicación programada y del cierre, del acabamiento, propio de la poiesis, del hacer técnico-instrumental, es decir, de la eficacia. De manera general, todos los estudiantes deben trabajar conforme a los objetivos establecidos y las estrategias digitales diseñadas por el profesor a fin de que el sistema funcione eficientemente, desplazando los intereses, las resistencias, los deseos, los imprevistos del alumnado. Es de esta forma que comúnmente se logra asegurar el control sobre los estudiantes, pero también sobre los profesores, quedando todos sometidos bajo el poder y la vigilancia burocrático-institucional, tendente al logro de los planes y finalidades instituidos.

Si, para Lévinas, la constitución de la subjetividad ética no existe previamente a la proximidad, sino que se da en el encuentro con el otro, conceptualizado como rostro desde la alteridad, en tanto una crítica a la autorreferencia del yo — la mismidad-, habría que repensar la fragilidad de la virtualización y, particularmente, el privilegio del monólogo en esta, como modalidad discursiva predominante en los 
espacios digitales, caracterizados por el discurso prescriptivo. Aquí, en la enseñanza y la "comunicación" digital, no siempre hay "nosotros" como otros — grupo de alumnos_-, sino un conglomerado de individuos, cada uno detrás de una pantalla, en donde la visibilidad del otro, de los otros, parece desvanecerse al igual que la responsabilidad con el otro, "como responsabilidad para lo que no es asunto mío o que incluso no me concierne [...]" (Lévinas, 1991: 89). La posibilidad de reconocimiento del otro y de solidaridad con el otro, como símbolo de una perspectiva humanística en la docencia, se advierte lejana en los encuentros virtuales sincrónicos e imposible en los asincrónicos. Así sintetiza Lévinas el enlace entre responsabilidad para con el otro y subjetividad desde el punto de vista ético:

Hablo de la responsabilidad como de la estructura esencial, primera, de la subjetividad. Puesto que es en términos éticos como describo la subjetividad. La ética, aquí, no viene a modo de suplemento de una base experiencial previa; es en la ética, entendida como responsabilidad, donde se anuda el nudo mismo de lo subjetivo. (1991: 89)

La enseñanza virtual tiende a favorecer la ausencia de una experiencia intersubjetiva y de un encuentro con el otro, al impedir que todos los sujetos puedan comprometerse en un trabajo relacional, en el que cualquier cosa puede ser posible, sin saber previamente hacia dónde se llegará. Inversamente a la docencia virtual, en el aula presencial y en el horizonte de la praxis, la enseñanza es proclive a atender a los sujetos en su experiencia concreta y respecto al sentido que ellos le otorgan, con la intención de abrir un camino en lo incierto, en lo imprevisto del acontecer formativo, comprometiendo a los profesores a una ruptura de la forma cotidiana de actuar, y a efectuar un cambio creativo de la ruta marcada por la planeación, las teorías y las ideas previamente asumidas.

Desde nuestra perspectiva, las prácticas educativas y formativas virtuales nunca podrán sustituir a la escuela, ni a la universidad, no comprendidas como establecimientos, ni como organizaciones, sino como "una red simbólica, socialmente sancionada, donde se combinan en proporciones y en relaciones variables un componente funcional y un componente imaginario" (Castoriadis, 1975: 184), y en donde se tejen interacciones e intersubjetividades, así como juegos de poder entre maestros, alumnos y autoridades.

Desde la formulación de la praxis, coincidimos con el pensamiento arendtiano y el derridiano relativo a que todas las acciones humanas y, por tanto, las prácticas educativas - caracterizadas por su inmanencia-, reclaman ser conceptualizadas como acontecimiento, comprendido este como natalidad (Arendt, 1993), como inicio de algo nuevo, algo imprevisto o algo sorpresivo (Derrida, 2001), algo contingente, como la singularidad de la pandemia, que advino violentando el curso regular de la docencia y de la vida cotidiana de las instituciones, sin que se hubiese podido anticipar su arribo con anterioridad. Funcionarios, maestros y estudiantes se enfrentaron a esa ruptura de lo previsto y programado para un curso escolar (horarios, currículo, programas, grupos, horarios, etcétera), al verse en la necesidad de encarar la llegada de esta pandemia no esperada y, con ella, la también llegada de nuevas formas de trabajo en un contexto definido por la confusión, la sorpresa y el desconcierto de alumnos y profesores.

En las instituciones educativas, la pandemia nos ha interpelado y desafiado a reconocer y aceptar una forma de responsabilidad ética en una "relación sin relación" singular con el otro, con los otros, con los alumnos como agentes de su propia autonomía, que a nivel institucional debe ser promovida de manera individual y colectiva por nosotros, los profesores. Por esa responsabilidad ética estamos convocados a acoger al otro, muy especialmente a los alumnos vulnerables que irrumpen en nuestras aulas virtuales y nos solicitan, a través de su rostro — como señala Lévinas — a ser escuchados, recibidos, atendidos en estos tiempos de contingencia que vinieron a trastocar nuestras certezas en el ejercicio de la docencia y a reiterar la fragilidad de nuestras planeaciones, previsiones y programaciones ante lo no esperado, lo no previsto. 
La pandemia nos ha emplazado tanto a reivindicar la educación como praxis, y esta como constitutiva de lo humano por excelencia, como a comprender la distinción entre el hacer manufacturero y el actuar humano, a pesar de reconocer el dominante pensamiento en el campo educativo sobre el hacer instrumental.

Cabe destacar que lo imprevisto, lo contingente, ha signado una ruptura en la vida de las instituciones educativas, pero sus actores, fundamentalmente maestros y alumnos, pudieron, en general, hacer frente ante lo inesperado, modificando sus prácticas habituales de manera sorprendente al evidenciar una gran capacidad de resiliencia y adaptación para garantizar la continuidad de los procesos educativos. Después de tantos meses y a pesar de la aparente pérdida de control sobre los alumnos, del sentimiento de impotencia y de angustia, así como de la ausencia de un horizonte definido, los maestros hemos aprendido a mantener la esperanza y la aceptación de lo incierto del mañana, de lo incierto de la educación y la formación; hemos aprendido a escuchar y darle la palabra al otro, al estudiante, palabra que de alguna forma significa liberación; hemos aprendido nuevas formas de relación intersubjetiva en ese lugar del encuentro: la pantalla; hemos tejido un horizonte de unión sin restricciones entre sujetos maestros y alumnos- que se reconocen mutuamente como sujetos históricos, únicos y singulares.

En fin, para cerrar y, contradictoriamente, abrir el debate, como hemos señalado, si convenimos que en el escenario-tiempo de la educación, como tiempo de emergencia, el advenimiento del sujeto se instaura a partir de interacciones, interpelaciones y de encuentros imprevistos y sorprendentes que rompen la continuidad del curso de las actividades, es preciso cuestionarnos: ¿en los espacios institucionales de formación y educación se otorga un estatus a la praxis en donde tenga cabida lo imprevisto, lo no esperado, lo contingente, la incertidumbre?; ¿los profesores aceptamos ser interpelados por los acontecimientos sorpresivos, particularmente en este escenario pandémico, y asumimos nuestra responsabilidad para cuestionar nuestras certezas, nuestras reglas, nuestras prescripciones?; ¿tienen los actores institucionales la capacidad de decidir y actuar frente a lo contingente?; ¿los proyectos formativos y educativos abren el camino para la autonomía, la libertad, la emancipación y la humanización de los alumnos como una perspectiva praxística?

\section{Bibliografía}

ARDOINO, Jacques (1994), "Praxéologie et Poḯtique". Recherche scientifique et praxéologie dans le champ de pratiques éducatives. Aix en Provence, Association Francophone Internationale de Recherche Scientifique en Éducation, pp.107-117.

ARENDT, Hannah (1993), La condición bumana. Gil Novales, Ramón (trad.). Barcelona, Paidós.

ARENDT, Hannah (1972), La crise de la culture. Huit exercices de pensée politique. Paris, Gallimard.

ARISTÓTELES (2014), Éthique à Nicomaque, en Les Échos du Maquis. Consultado en $<$ https://philosophie.cegeptr.qc.ca/wp-content/documents/\%C3\%89thique- $\%$ C3\%A0-

Nicomaque.pdf $>(23 / 06 / 2021)$.

ARISTÓTELES (1988), Política. García Valdés, Manuela (trad.). Madrid, Gredos.

CASTORIADIS, Cornelius (2000), Le monde morcelé. Paris, Seuil.

CASTORIADIS, Cornelius (1975), L'institution imaginaire de la société. Paris, Editions du Seuil.

Centre National de Ressources Textuelles et Lexicales (2012), "Contingence", en Ortolang. Consultado en <https://www.cnrtl.fr/etymologie/contingence> (7/06/2021).

DeLEUZE, Gilles (1995), “L'immanence : une vie”, en Philosophie, n. 47, pp. 3-7. 
DERRIDA, Jacques (2003), Voyous: Deux essais sur la raison. Paris, Galilée.

DerRIDA, Jacques (2001), Dire l'évènement, est-ce possible? Séminaire de Montréal, pour Jacques Derrida. Paris, L'Harmattan.

FORAY, Philippe (2001), “Hannah Arendt, L'éducation et la question du monde”, en Télémaque. Caen, Presses Universitaires de Caen. Consultado en <https://www.cairn.info/journal-le-telemaque-2001-1-page79.htm> (22/06/2020).

GARFINKEL, Harold (2006), Estudios en Etnometodología. Pérez Hernáiz, Hugo Antonio (trad.). Barcelona, Anthropos.

HeidegGer, Martin (1951), El ser y el Tiempo. Gaos, José (trad.). Ciudad de México, Fondo de Cultura Económica.

IMBERT, Francis (1992), Vers une clinique du pédagogique. Un itinéraire en Sciences de l'Éducation. Vigneux, Matrice.

LÉVINAS, Emmanuel (1991), Ética e infinito. Madrid, La balsa de la Medusa.

PerRENOUd, Philippe (1999), "Gestion de l'imprévu, analyse de l'action et construction de compétences",

Education Permanente, $\quad$ n. $^{\circ} \quad 140 \quad$ Consultado $\quad$ en
<https://www.unige.ch/fapse/SSE/teachers/perrenoud/php_main/php_1999/1999_16.html> $(24 / 07 / 2020)$.

REAl ACADEmia Española (2020), "distancia", "distanciamiento", en Diccionario de la lengua española. Consultado en <https://dle.rae.es/> (24/07/2020).

SARTRE, Jean Paul (2004), La nausée. Paris, Gallimard. 